\title{
Moments of Intersection, Rupture, Tension: Writing and Academic Disciplines in the Semiperiphery
}

\author{
Amy Zenger \\ American University of Beirut, Lebanon \\ John Pill \\ Lancaster University, UK
}

This chapter focuses on the relationships between writing and academic disciplines in a space of academic practice in the semiperiphery, as conceptualized in world-systems analysis. Defined by its role in mediating between the core and the periphery in cultural, economic, or political domains, the semiperiphery acts as a conduit for centre goods and culture towards the periphery, and has also been credited with the potential to challenge core practices and thinking and to promote innovation. To investigate the value of a world-systems analysis approach for the study of academic writing, we bring it to bear on our reading of existing data from interviews with eight multilingual faculty members working at a long-established Middle East university that uses English as the medium of instruction. Analysis of their responses allowed us to interrogate the concept of the semiperiphery and identify how it may be experienced in the lives and scholarship of individuals. We adopt a world-systems perspective that situates European academic writing in a core location linked systemically to particular semiperipheral and peripheral locations of scholarly production and teaching. Our findings suggest that scholars are not affected to the same extent or in the same way by their situation in a semiperipheral context. Nevertheless, the concept of the semiperiphery is useful for articulating the potentials of the situation - particularly for the purpose of evaluating academic production by disclosing intellectual work that might otherwise go unrecognized - as well as for accounting for specific constraints. We illustrate a link between academic disciplines and global interrelationships, framing academic 
writing as a performance that can both enable participation in an academic field and work to contest disciplinary norms or boundaries.

Writing studies and language studies scholars have long been interested in the role writing plays in constituting academic disciplines. Histories of how academic disciplines developed (Bazerman \& Paradis, I99I; Russell, 2002), models of how disciplinarity works (Flowerdew \& Costley, 20I7; Gere et al., 2015; Prior, 1998, 2009), and scholars' observations of how writing is called upon to enact the work of a discipline (Tusting \& Barton, 20I6) all inform writing programme design and approaches to teaching undergraduate and, more pertinently, graduate student writing. Gere et al. (2015) note a distinction between disciplines as epistemological forms, governing knowledge creation and dissemination, and disciplines as institutional forms, most often university departments, that exert power over disciplines in terms of employing and promoting scholars, maintaining curricula, and mentoring new scholars. Disciplines are also represented in dynamic terms, as complex networks that are open to interactions with other fields while also being anchored in their fundamental concepts and approaches (Prior, 1998, 2009; Thaiss \& Zawacki, 2006). Tusting and Barton (20I6) study how managerial strategies shape disciplinary writing practices of scholars in the UK. Similarly, in this chapter, we consider how sociohistorical factors shape the practices of writers in a semiperipheral context.

Our study derives from a project designed to promote conversations and develop local understandings about academic writing in one institution, a university in the Middle East at which English is the predominant medium of instruction and communication within a broader multilingual environment. By representing the work of successful multilingual scholars at this university in their own words, we aim, in the broader project, to highlight for students and faculty the strengths of multilingual writers as they navigate teaching, research, and publishing in their disciplines across languages, across socio-political contexts, and across academic and public audiences. In this chapter, we consider how individual experiences of scholars as reported to us appear to be shaped by or to engage with an assumed position of the institution within a core-periphery framework. The framework we use comes from world-systems analysis, which was first put forward in the 1970 s by the sociologist Immanuel Wallerstein and has since been taken up by researchers in a wide number of fields (e.g., sociology, politics, economics; see Babones \& Chase-Dunn, 20I2). The approach proposes three fundamental categories, none of which is meaningful in and of itself, but all of which are significant 
because of their relationships to each other: core, periphery, and semiperiphery. Positing the university in our study as a semiperipheral space, we interrogate the concept of the semiperiphery as an analytical tool to help understand disciplinary writing and its teaching in this institution.

In the sections that follow, we present an overview of world-systems analysis, focusing on the category of the semiperiphery, describe the institutional context and our broader research project, offer evidence presented through individual interviews with faculty members, and discuss what we learn from considering our data through this lens.

\section{World-Systems Analysis and the Semiperiphery}

Immanuel Wallerstein characterizes world-systems analysis as a "knowledge revolution"- a challenge to the accepted ways that knowledge has been categorized (Wallerstein, 20I2, p. 517). In the mid-twentieth century, he began developing his interpretive approach as a framework to coherently address his concerns, namely: "concern with the unit of analysis, concern with social temporalities, and concern with the barriers that had been erected between different social science disciplines"(Wallerstein, 2004, p. 16). Wallerstein's approach questions the boundaries of disciplinary formations that emerged in the nineteenth century and proliferated, especially the division that emerged between the arts and the sciences. Our current academic disciplines developed primarily in universities in Germany, France, the United Kingdom, and the United States, evolving within and closely tied to the long historical period associated with the development of the capitalist system. Rejecting nation-state borders as the primary spatial unit of analysis, the approach proposes instead a broader multi-state world-system to argue that features of core or periphery are not inherent, but rather derive from their positions within a system of political, economic, and sociocultural relationships. Wallerstein is careful to note that in this usage, world-system does not imply the world; rather it points to $a$ world - a set of locations that are connected through and defined by systematic relationships (2012). As Wallerstein (2004) stresses, "In world-systems analysis, core-periphery is a relational concept, not a pair of terms that are reified, that is, have separate essential meanings" (p. I7). In temporal terms, drawing on the work of annales historians, world-systems analysis rejects the event as a unit of political and social analysis in favour of developments of much more extended duration—not so extended, however, as to become, in effect, universal laws.

Wallerstein's approach, like other core-periphery theories, allows him to address inequalities but also avoid representing nation-states and sociocul- 
tural phenomena in absolute terms. For example, he argues that underdevelopment must be understood "not as an original state, the responsibility for which lay within the countries that were underdeveloped, but as the consequence of historical capitalism" (Wallerstein, 2004, p. I2).

While the intervention represented by world-systems analysis can be readily understood as applicable to social and political disciplines, Wallerstein argues that this analytical approach is relevant for all domains of knowledge. Writing about the humanistic disciplines specifically, he says:

The world in which we are living is, I contend, a capitalist world economy. It has its history, its structure, its contradictions, its prospects. I try to study this directly. Others study it implicitly. I think it might help us all if the latter reflected more openly on what it is they are really doing.... [All disciplines tell us about] the world in which we are living now. (20II, p. 226)

In research on writing, core-periphery studies take a broad, structural perspective of academic practices in order to understand forces that shape inequalities in the material resources available and in practices such as peer review for publication, criteria for promotion and tenure evaluations, and resources available for travel, research, and teaching. Studies adopting these perspectives have considered publication practices, language choice (English as a lingua franca as opposed to local languages), and rhetorical styles (Canagarajah, 2002; Lillis \& Curry, 2010). Karen Bennett (2014) focuses on the idea of the semiperiphery for an edited collection about academic writing in Europe, specifically in areas she presents as semiperipheral in relation to other parts of Europe. In her introduction, Bennett notes that universities in the semiperiphery perform boundary work between the core or centre and the periphery, frequently acting as "buffer zones" and "conduits for knowledge flows emanating from the centre" to serve institutions and people in more peripheral locations (p.3). Given that universities in the semiperiphery often depend on centre institutions for funding and serve to translate knowledge from the core to the periphery, they can be portrayed as derivative. Bennett counters this perception, however, by arguing that the semiperiphery is more aptly described as "a place of tension ... effervescent with possibilities, allowing dominant attitudes to be challenged and new paradigms to arise in a way that would be unthinkable in centre countries" (20I4, p. 7). She argues that the semiperiphery plays an important role in the global university system.

While Bennett's (2014) volume considers locations on the edges of Europe as semiperipheral, the current study moves beyond the continental border to the eastern coast of the Mediterranean Sea. Prompted by Bennett's claim for 
the value of semiperipheral contexts and aware of our own observation of creativity and dynamic tension in the stories related in our research data by academics at a university in Lebanon, we looked in our data specifically for reference to the concerns of the semiperiphery.

\section{Context of the Study}

The Syrian Protestant College was founded in Beirut in 1866 by missionaries from the United States. Initially the language used in teaching was Arabic but in the late r87os English was chosen as the medium of instruction. The institution became the American University of Beirut (AUB) in 1920, when its proselytizing mission ended (Anderson, 20II). Women were accepted as students at AUB from 1922. The university now follows the American liberal arts model of higher education and is accredited in the United States by the Middle States Commission on Higher Education. The university's mission is "to provide excellence in education, to participate in the advancement of knowledge through research, and to serve the peoples of the Middle East and beyond" (American University of Beirut, 2019, p. 5). It is a private university with about 9,000 students representing 89 countries; 78 percent of the student body has Lebanese citizenship (American University of Beirut, 2019). The over 900 full-time faculty members are a similarly international group. Many AUB faculty members of Lebanese origin have earned postgraduate qualifications at North American or European universities and subsequently taken up academic posts at the university.

In a history of AUB, Anderson (20II) describes how the university "has stood at a vital intersection between a rapidly changing American missionary and educational project in the Middle East and a dynamic quest for Arab national identity and empowerment" (p. 2). The history sets out to show how students "used both of these American and Arab elements to help make the school not only an American institution but also one of the Arab world and of Beirut, as the very name, the American University of Beirut, indicates" (Anderson, 20II, p. 3). This perspective explicitly sets up the institution as mediating between educational and cultural worlds or, we suggest, as being situated in the semiperiphery. The civil war in Lebanon (1975-1990) had catastrophic effects for the country as a whole and the university, and the subsequent process of rebuilding has been gradual. Academic tenure, which was suspended during the war, is currently being reinstated, and AUB is actively seeking to raise its international standing as a research university. As our interviews show, these goals have an impact on faculty members, as the university looks towards the core and to matching the standards and expectations 
set by universities in the United States deemed to be comparable with AUB concerning, for example, the types of research and publication that are valued in applications for promotion and tenure. ${ }^{1}$

The university expresses characteristics of its home country. Lebanon can be described as a multilingual society, where Arabic, the official language, is widely supplemented by English and French in everyday life. Patterns of language use are complex and vary according to domain. For example, Arabic is the preferred language of political discussion, while text messaging often uses a mixture of Lebanese Arabic, English, and Arabizi, that is, Arabic written using Latin script (Esseili, 20I7). In the school system, the official requirement is that mathematics and science are taught in English or French while other subjects are taught in Arabic. (For discussion of the language use in science classes at Lebanese schools, see Salloum \& BouJaoude, 2020.) Unofficially, further subjects are likely to be taught in English or French, particularly in private schools, thus reducing the amount of education students receive in Arabic (Orr \& Annous, 2018). Lebanon's ties with the French language are demonstrated through its membership of the Organisation internationale de la francophonie (https://www.francophonie.org/).

Researchers writing about the current linguistic situation in Lebanon are likely to refer to the country's geographical location between the Middle East and Europe (the Western world) and to the historical relationships arising from this, from ancient Phoenician commerce around the Mediterranean Sea to the French mandate in the interwar period; they will also refer to economic and pragmatic reasons for Lebanese to know several languages, namely, to facilitate trade and to gain employment within and outside Lebanon (see, e.g., Esseili, 20I7; Shaaban, 20I7). Some scholars take a critical approach, for example, about the "linguistic imperialism" demonstrated in the growth of English as a medium of instruction in Lebanese schools (Orr \& Annous, 2018).

In this section, we have presented a view of AUB as an institution and of its wider context in Lebanon. In our opinion, this view demonstrates characteristics of the semiperiphery: The name of the institution itself indicates its allegiances, first to an American model of higher education taught in English - a model drawn from a core country for use elsewhere (cf. other institutions named "American University" around the world), and second to Beirut, a city widely seen historically and in current times as a cultural and economic intersection between East and West. The mission of the "American

1 Our data were collected before the financial, economic, political and social crises in Lebanon in 2019-2020 and the explosion of 4 August 2020, which caused great damage to Beirut and her people. The full consequences of these major disruptions are not yet apparent. 
University" to "serve the peoples of the Middle East" situates the institution in the mediating role ascribed to the semiperiphery. Having made the claim that AUB is a promising context for an investigation of the concept, we now proceed to see how individual faculty members at AUB represent themselves and their disciplines in terms of the constraints and affordances of the semiperiphery as posited by Bennett (2014).

\section{Methodology}

The aims of the research project were broader than may be apparent from the data presented in this chapter. We wanted to collect individual literacy narratives from multilingual faculty members at AUB to investigate their views on how they developed their own language and writing abilities to perform at a high level in their academic disciplines. We believed this would at the same time shed light on disciplinary and institutional writing practices. To share this insight, we aimed to report on the language learning and writing strategies of multilingual language users identified by the participants (the current paper is one part of this project) and to present these findings in an easily accessible format as a resource for reflection, discussion and (self-)development in the AUB academic community and beyond. Our specific intention was to create a website containing edited video clips drawn from the interviews with our participants along with notes to prompt viewers - undergraduates, graduate students and faculty members at AUB and elsewhere-to relate their own practices and goals to the views and experience shared by successful academics who they might recognize at the university and who perhaps had a similar background to their own. ${ }^{2}$ Therefore, the study was not designed specifically to interrogate the notion of the semiperiphery. Nevertheless, when we were introduced to the concept in Bennett's (2014) edited volume, we anticipated that it would be productive to consider our data from this perspective.

Ethics approval for the study was given by the university. Members of the AUB faculty were invited to take part in the study as a convenience sample. We asked multilingual academics whose first language was not English and sought to represent a variety of disciplinary areas and a range of research and teaching experience in these disciplines. We also sought a gender balance. Participants had to agree to being video-recorded and to allow an edited version of this recording, including their name, to be published on a freely accessible web page. They would be able to review the proposed video clips and ask for revisions to be made before publication.

2 This project is still underway. 
Data collection was carried out in the first six months of 2017. In preparatory small-group meetings involving two or three academics and then in individual video-recorded interviews lasting an hour or more, research participants were prompted to reflect on three broad topics: the nature of writing in their academic discipline, their experiences as a multilingual scholar, and their approaches to teaching writing. As we did not want participants to feel constrained in what they spoke about, an indicative set of prompts was provided in advance of the interview rather than a more structured protocol. The interviews with our eight participants were completed in English. Transcripts were subsequently prepared and then studied and annotated by the two researchers iteratively to establish themes in the dataset.

\section{Scholar Interviews}

We met with and interviewed eight scholars, working a range of fields: comparative literature, linguistics, ecosystems management, systems management, sociology, anthropology, biology, and education. Our participants had worked at AUB for between four and 25 years when the interviews were recorded. In this paper, we focus on interviews with four of these participants. These interviews included topics that we see as relating to issues of the semiperiphery. Content from the interviews with the other four participants is not presented, because it is not directly pertinent to our argument. However, these interviews do of course indicate that issues of the semiperiphery are not what immediately comes to mind for all academics working in our research context. In the discussion section, we consider why the contributions of the four other interviewees covered different ground. To reiterate an important point, our data were not collected originally with the intention of exploring the concept of the semiperiphery; absence in the data of content relevant to this concept is consequently unremarkable, indicating the personal nature of the interviews and the participant-led methodology employed. On these grounds, we have chosen also to present our data for each interviewee in turn rather than thematically with interviewee comments as illustration. An overarching finding in this paper is that the semiperiphery appears differently in the stories of individuals, and we believe the structure used here captures better this personal manifestation.

\section{Saouma BouJaoude}

Saouma BouJaoude was educated in Lebanon and the United States. He was a science major as an undergraduate at AUB and is now a professor in the 
university's department of education. His research considers how science is taught to children at school. BouJaoude indicates that he is aware of his location on a core-periphery continuum and that he seeks to exploit this: "AUB wants me to write in English and I want to be promoted." ${ }^{3} \mathrm{He}$ finds the requirement to publish in English in international journals can be managed by being strategic and finding a niche. In talking about his work, he also exemplifies how those away from the perceived centre may be well placed to see differences in the traditions and behaviours of the core and therefore able to benefit from their broader perspective on the discipline.

In his interview, one of the main topics he discusses are strategies to get published and the need to be pragmatic: "since AUB wants me to publish in high-quality journals in English, therefore I have to do it ... It can be done if you put your mind to it." BouJaoude explains the problem as he sees it and how he deals with it:

There are a lot of issues that are mature in the USA or in the UK-they have been studied and studied and studied. Whatever you do here [in Lebanon] is not going to be innovative enough to be published in a journal. You have to find a niche-a niche, which is really interesting to journals, meaningful to you, and innovative. I think this is how I describe my own decisions to do certain kinds of research here to be able to meet the requirements of the university. I started doing things related to evolution, and the reason for that is because this is a context that is different than the USA and Europe, in that we have Muslims and Christians, and therefore you can look at how students think about evolution in a very different context, but it's useful for journals in the West, because, more and more, they have diverse populations ... So, this is an area that I decided to take and then, from there on I looked at how I can introduce language as a factor in the studies that I do, because I thought it's very useful to Lebanon, but at the same time it's giving a very different perspective. Teaching science in a multilingual context is very different from teaching science in a monolingual context.

As well as finding a topical niche-in his case, religion and cultural as-

3 Because interview transcripts are not accessible to our readers, we do not mention page numbers or line numbers in our citations, but simply refer to the interview transcript as a whole. See the previous footnote. 
pects of science education - and explicitly considering issues of language use in science classrooms, both of which are novel and interesting from a core perspective as well as having potential impact on local teaching practice in Lebanon, BouJaoude also reports seeking a methodological niche as a way to make his research attractive for publication. He gives an example of research that involved collecting quantitative and qualitative data independently from the same class of students to investigate whether the two approaches produced compatible findings.

Another major topic in BouJaoude's interview concerns his recognition of distinct cultural perspectives on research and research traditions in the discipline of education. He is aware of practices and expectations varying in different contexts, which might not be so apparent to "insiders," that is, scholars working in the core who take for granted that their "mainstream" views are ubiquitous. As a first example, BouJaoude sees his disciplinary perspective (in science education) as "Anglo-Saxon, whether it's UK [or] the US." He comments on previous collaboration with colleagues at the Université Saint-Joseph, the oldest French-oriented university in Beirut, founded in I870, and how he found the French traditions in his field to be very different: "Even the theoretical frameworks of the French system are very different. The literature in the science education is very different." BouJaoude gives an example from a project with the Lebanese Ministry of Education to develop a trilingual (Arabic-English-French) glossary of pedagogic terminology: the French term transposition didactique - "how you change the science of the scientist to science that is taught in the classroom" is not found in English. He states that "the English tradition of science education is very different from France and Germany - the theories they research, sometimes there is a crossover, but it's different." He also refers to research indicating that scholars in the discipline read different journals in Europe and in the United States.

As a second, broader reflection of differences between educational traditions, BouJaoude shares his opinion on the writing skills of AUB students, noting that students "who have been in good French schools [i.e., Lebanese schools where French is the first foreign language] do much better in writing than those who come from good English schools." He attributes this variation to a lack of focus on writing in many of the schools teaching science in English (in Lebanon), where science knowledge is more often checked using multiple-choice questions than through student writing. BouJaoude discusses an area of research around writing to learn in science education: "when you're writing, you're expressing your ideas and communicating to an audience ... The process of writing is essential in the writing of science-science is all about critiquing and defending arguments."The processes involved in writing 
promote reflection and the development of metacognitive skills to critique one's text. He explains how the French-oriented education system uses an approach he terms "analysis of documents" (commentaire de texte), where the teacher gives students "a document that describes something scientific and they have to analyse it and relate ideas to it" in writing. He sees experience in doing this task to give French-educated students an advantage over English-educated students.

The third example of disciplinary difference comes through BouJaoude's experience of educational consultancy work in various countries in the Middle East and North Africa. He is aware of a need to mediate between academic traditions, between the core and periphery. In terms of academic production, he notes that writing in the English and French research traditions is quite similar when compared to Arabic practice, with its more formulaic approach and literature reviews with "no integration of the research articles to come up with a gap so that you can address it." The discipline of science education itself is hardly visible in the Arab context, with few publications in any language. BouJaoude believes the prevailing view is that science research must be positivist and quantitative, which is not the case for many studies in science education, his field of expertise.

This insight into various expressions of disciplinary difference is more likely obtained by an outside observer trying to understand core-focused practices and traditions in order to engage with them. BouJaoude comments during his interview, "You had to find ways of making this meaningful."

\section{Sari Hanafi}

Sari Hanafi is a professor of sociology who studied engineering at Damascus University, before deciding to study sociology. He obtained his doctorate in sociology from a French programme in Cairo. His areas of research include migration issues, transitional justice, and the sociology of knowledge. His work has led him to conduct scholarship in Arabic, French, and English, making significant contributions in all these languages.

As a scholar whose research interests include knowledge production, Hanafi articulates his consciousness of his semiperipheral location as a scholar very clearly. During his interview, he recounts how this evolved over time and informs decisions he has made as a researcher, editor, and teacher. $\mathrm{He}$ strongly emphasizes the importance of making knowledge accessible for diverse audiences. This principle can entail translation, which in his account is a generative intellectual project in itself. He also advocates teaching disciplinary courses to graduate students in Arabic as well as English, recognizing 
the need to theorize in each language. Furthermore, Hanafi extends his willingness to engage in controversy to interventions in disciplines themselves, for example by expanding the boundaries of the literature or by challenging a core conceptualization.

Hanafi argues that "You need to publish in language accessible to people." "Social science need always to ask ourselves as scholars I mean "knowledge for what, for whom?" he says. In his own field, it is important to translate scholarship into Arabic because "you don't want to downplay language, vernacular language into just a fieldwork, I mean just a kind informational articles, while theory [is] kept to be taken from those who write in English or French." This is a matter that the scholarly community is not addressing enough, in his view. When he surveyed the publications produced by all faculty members at AUB over a period of three years, he found that only two out of 270 books were published in Arabic.

The process that Hanafi calls "arabizing" social science entails advocacy, translation, and instruction. As a professor, he tells his students "The whole [of] social science is to delay your value judgment ... to [a] maximum. So, I would say the same, that handling different languages ... is definitely an enabler of this sense of humanism, relativism, multiculturalism. That things can be said, done in different ways, I think is so enabling and refreshing and inviting for critical thinking." He advocates including elective courses in the curriculum in which students are taught social science in Arabic, so that they are not limited to learning to theorize and communicate in English.

Translation, usually from English into Arabic, requires sophistication to be able to follow the arguments precisely and at the same time use the style, terminology, and form of Arabic academic sociology. Sometimes, the translation must also navigate political consequences in the real world, as the following account about Palestinian refugee camps in Lebanon shows:

I work on different modes of governance of refugee camps and ... I heard a very harsh criticism ... from popular committees but also from a high-rank man in police who came to talk and he told me "If you ever use the word 'governance' in a refugee camp, I put you in the prison-Palestinians can administrate their camps but governance is something related to sovereignty, so we Lebanese we govern the camps, but they administrate the camps." .. . This guy still think[s] that "governance" only about "government" . . . and "government" related to sovereignty. So, we changed . . . the first version was "hawkama," which is "governance" of the camps, and the second version of 
this report ... when it was published as [an] article, I changed it to "administrating camps"- "idaret al-moukhayamat" . . . just to appease the criticism of what I wrote.

In the examples he presents, Hanafi suggests translation as an important element in the production of knowledge and in performing what would in world-systems terms be identified as mediation within the system.

Hanafi's insights into writing and disciplinarity were often hard-won through experience as he navigated across disciplinary traditions and linguistic boundaries. His account of his own enculturation into academic publication is punctuated by sometimes painful experiences of being schooled by reviewers, editors, or mentors into conforming to different linguistic and disciplinary expectations. He recalls how an early mentor in sociology told him, "Look you are very stingy in words and this is the problem of your education, background as a civil engineer ... so I want to liberate you from this." From this interaction he gained the understanding that "social science need[s] really to handle complexity of social phenomena, and complexity cannot be handled by 'yes,' 'no'." On a different occasion, a colleague removed "all the metaphors" in a presentation Hanafi had written in Arabic, explaining that they "were not scientific language." It was many years before Hanafi questioned the advice of his respected colleague and recognized that "it's a kind of symbolic violence when we say 'no, it's a fact, it's zero/one'." In another experience Hanafi shares with beginning writers, the editor of a collection contacted him about his contribution, and her first comment was: "I will take all your footnotes and put them inside of the text and take your text and put it in the footnote." She told him, "Your footnote is so important, and your text is so boring!" Hanafi says, "She noticed that every time I want to say something interesting, if you like, I got hesitant and I want to extrapolate ... so I put it in the footnote."

Hanafi also notes that in many universities in the Arab world, students may complete a degree without having received guidance or instruction in academic writing. As editor of Idafat: The Arab Journal of Sociology, Hanafi grew so tired of receiving submissions with structural and stylistic weaknesses that he created a writer's guide in Arabic, drawing upon his own experiences of learning to write academic texts in sociology. He published "Common Mistakes in Sociological Writing" (20I4) as an editorial and, after posting it on the website https://www.academia.edu/, he noted that it has been downloaded many times. The piece encourages scholars in the Arab world to feel confident in publishing.

At times, Hanafi has encountered tensions related more to disciplinary 
bodies of shared knowledge or biases in a field, rather than languages per se. "This sometimes bring headache," he notes, "but really this is how I see science progress-I mean with controversies." For example, one of his efforts to publish an article in an American journal was not successful because it was based on literature central to European scholarship but failed also to mention authors on the subject who were more well-known in the United States. Hanafi also notes that "We never say sufficiently that academia in the West can also bear its political biases." As evidence of this, he recounts his experience of publishing an article critical of the way that Human Rights Watch reported rights violations in Palestine. After being reviewed by two English language journals, each of which circulated it to several referees, the article was rejected. It was eventually published in French and in Arabic but has never appeared in English. For Hanafi, this is "a pity" because the audience that needed to hear his criticism became less likely to hear it. He is committed to diversifying his audiences even to the extent of courting controversy.

While recognizing that disciplines originated historically in colonialist enterprises, Hanafi considers attempts to decolonize knowledge by directly rejecting core disciplinary traditions a trend that "had led nowhere." He aspires to follow the wisdom of Abd al-Qahir al-Jurjani, an Iranian linguist of the tenth century, who believed that "language has a lot of potentiality [in] resolving problems." As Hanafi explains al-Jurjani's ideas:
You keep interpreting the sacred books ... and the language will enable you more and more to understand social actors, what kind of meanings they put for . . . their actions. The meanings go beyond the vocabulary you have. So, stretch your language ... and language will end up by bridging.... This way, I keep the social science immune from too much normativity . .. and the language will do the miracle of bridging.

Finally, for Hanafi, "writing is part of the research method." "It's not something you do once your field work is over," he says, "not once you say 'look the scientific part is done' and now it just a kind of dull translation of factual things you observed, you quantified et cetera into a language that is accessible to public or 'jargon-al' for your peers."

\section{Sirène Harb}

Sirène Harb grew up in Lebanon during the civil war, studying at AUB before going to the United States to earn her doctorate. Her academic field is American and comparative literature. In her interview she tells her personal 
story, reflecting on her development as a writer in three languages and as an academic. This educational and professional history makes it clear that Harb inhabits the semiperiphery. She is conscious of disciplinary and institutional pressure affecting what and how she writes and recognizes a tension between her individual goals and externally imposed requirements: she asks, "Why am I putting so much effort for something that has no guaranteed result?" This feeling is familiar to many academics, but we suggest that it is a particular feature of the semiperiphery if scholars in this context are sensitive to their situation, as Harb is, having awareness of the acceptability of the range of options available as well as of the obligation to conform to assumed norms of the core. Harb's experience of being educated and becoming an academic in a semiperipheral context-multilingual and culturally diverse-makes her valuable as a teacher and academic mentor, to nurture others growing up in the same context.

On the topic of tensions between compliance and creativity, Harb recounts two childhood memories which anticipate her experience as an academic. She grew up using Arabic at home and French at school; she enjoyed reading and writing poetry. When she showed examples of her poetry in French to her schoolteachers, she was told they didn't rhyme: "for them this was the most important thing, and I saw with one of them, she had divided the verses into like stressed, unstressed syllables." Harb now sees the criticism as an "early insight into the difficulties also that I will be facing as a writer who does not necessarily want to follow these commonly accepted rules, except when they make sense to them."

Her second account concerns practicing analyse de texte at school, a task Harb enjoyed: "very often I could get away with not answering it the way it should be ... by justifying why is it that it would be more important or more interesting to look at it in a different way." However, as end-of-school exams approached, she was instructed to keep to what was expected in order to pass. Harb presents this imposition positively, as a realization that she must take account of her audience, "the imagined examiner ... a projected figure."

Now, as an academic writer, Harb writes literary criticism, enjoying its challenges "up to a certain point." She notes how disciplinary expectations are moving away from a primary focus on the text towards theory and context. She teaches her students that academic writing is an intervention in an ongoing conversation but is conscious how growing specialization and the variety of analytical tools available make any intervention increasingly difficult for novices, and for herself. Harb states, "the challenge is really about negotiating the boundaries of what you know is wanted from you and what you want to really put in ... a piece of analysis", which reflects her reported childhood 
experiences. She contends that "we cannot make it work if we have to stop at every term that we use and say 'oh but I have to qualify" and asks "what's the margin that I have? how much can I negotiate?”

In her interview, Harb notes that she sometimes questions why she writes "except that this is part of the requirements of the profession" and indicates that her creativity is limited by these constraints. She explains how the imagined voice of the reviewer or reader can affect this obligation to be a productive writer-the consequences of what this voice says "could be very positive but also extremely debilitating", leading to the loss of one's voice in the disciplinary conversation and, potentially, even to the loss of one's job: "there is no place of safety ... [without] tenure or ... a certain system that would allow for productivity to take its time." Harb feels that institutional requirements often do not align smoothly with the creative path: "you start projects, but they don't materialize in the way ... that's institutionally readable or legible."

Such tension-recognizable to all academics—is brought into sharp focus viewed through the lens of the semiperiphery. An individual's creativity seems dampened due to inflexibility imposed from elsewhere, and the scholar must learn how to deal with this dilemma. A positive consequence of this experience is that the scholar is then well placed to help others deal with similar challenges. Harb came late to English, as a medium of her education and then as an academic discipline in English literature. In her interview, she reflects on how she has learned to do what she does. Being able to reflect in this way allows her to draw on her own experience to help others following a similar educational path. Again, this is not a feature exclusively of those in the semiperiphery; however, the context can be seen to promote a capacity for reflection in some of its inhabitants, including Harb, which allows them to serve effectively as educators and mediators in their situation.

Through the biography in her interview, we can reflect on Harb's relationship with English as a language and subject of study through her education in Lebanon, posited as a location in the semiperiphery. She first experienced English in school as a second foreign language (after French). She describes first engaging with writing in English in the communication skills programme when she entered AUB as an undergraduate majoring in biology, which was planned to provide a "day job" to support her creative writing. She appreciated the structured and clear approach to writing that was taught: "I really loved the straightforwardness of the English texts that I was reading." English writing is an object of study for Harb- "a relationship with ideas"in contrast with her personal, instinctive connection with writing in other languages. She chose to study English (rather than French) literature to avoid losing the intimacy of her relationship with French while also recognizing a 
"freedom to speak [which] can say much more than one would expect it to" through studying texts in a new language.

Coming to teach English writing skills to Lebanese students during her career, Harb draws on her experience of consciously learning how to write in terms of processes (e.g., free writing) and labels (e.g., topic sentences), encouraging her students to "observe how you build knowledge personally also, your process of knowledge building", as she did. The approach has received positive feedback and indicates the importance of students seeing how their teacher succeeded on an educational and developmental journey that they recognize as like their own. Harb also talks with her literature students about how they might be able to intervene in the academic conversation by starting from their own experience. She reminds them that "this author himself herself, they were in your shoes some time ago." This capacity for self-reflection and empathy makes Harb a valuable educator in a context where she shares the background of many students.

Harb is working out the challenges of her discipline on a daily basis. She is consequently well-placed to educate and support students at AUB. What concerns her is the possibly limited extent of her employing institution's recognition of the need for such "local" expertise, while it prioritizes the emulation of characteristics of the core.

\section{Salma Talhouk}

Salma Talhouk is a professor in the department of landscape and ecosystems management. Her research has moved from purely scientific investigations to a more social science approach to studying ecology and landscape. In Lebanese schools, she was educated in French, Arabic, and English. During her doctoral training in landscape horticulture, which she undertook in the United States, Talhouk specialized in molecular fingerprinting.

In her account of her work as a scientist engaged in her community, Talhouk shows that she has been led to wrestle with her disciplinary identities and to invent or adopt unfamiliar modes of researching and writing. Her literate abilities in French, English, and Arabic have all been necessary to the new directions her academic work has taken, deployed according to the needs of the work.

When Talhouk returned to Lebanon to take up an academic position, she set up a laboratory and continued her scientific research. She reports experiencing a turning point in her work in mid-career:

I felt like I had to make a decision about my life, not my work, which is that I know I can do the research and publish, but at 
the same time, I know that it's useless for the country. Because, for example, I would collect different olive trees or pistachio trees and I will do the molecular fingerprinting, but then I know that these trees are going to be destroyed and cut because of the social set-up.

She dismantled her laboratory and sought to continue her work in innovative directions. She recognized that her action represented a risk in terms of her academic career: "In spite of the fact that we have promotion and tenure pressure and all these things, I decided to go with my gut feeling." She says, "As an academician, I feel that our duty is to serve the society."

Reflecting on the deep specialization that is encouraged and rewarded in academic fields, Talhouk comments, "If you look historically about people, they tell you 'he used to be a physician, and a plant expert, and a poet, and a painter, and this and that' and it was not strange to do many things. Now, it's strange to do many things, and this is ... it doesn't work in developing countries not to do many things." She observes that "it's sad that people have to fit you into a discipline, because when you are in a developing country at least, you just respond to what's around you, and you do what needs to be done."

Since moving away from strict laboratory investigation, Talhouk's work has taken two main directions. On one hand, she has invested her energies in a range of projects that address the general public on matters related to the environment. She established an academic centre for nature conservation research and communication to sponsor projects. One project sponsored by the centre she describes as "participatory mapping" of biodiversity, where "people can do a self-assessment in their own villages", a process completed by 80 villages to date. Her work in this direction also includes several publications. She has written a children's book in Arabic called The ABCs of Nature (2017). Another book project she developed, Trees of Lebanon (Talhouk et al., 2014), is a bilingual illustrated guide to local trees. This project is unique in that the trees are described and named from the perspective of the knowledge and language of nature of the region. Talhouk's aim was to foster people's sense of connection with nature and encourage their investment in reforestation projects. She had noted that "if they don't feel that these trees are part of their history or their heritage, why would they connect?" In the book, she "tried to find, to create the story that links us. And it wasn't easy, because all the information is produced in Europe and the US."

Her work has also turned towards new kinds of academic research, disseminated through conferences and academic publication. She studies "people and their perception and attitude towards nature and conservation." As 
her work moves away from pure science towards sociological studies, she says "I'm like still a student in this other field that I have decided to go into, which I don't know what it is." Her previous training did not prepare her in the methods she needs to follow, or in how to write about her findings. She often feels that her work is "between the cracks" of different disciplines. "It's starting to shift, but it's very difficult," she says.

Her approach to conservation is also critical of practices that are currently in place. For example, reforestation projects, which she suggests should be managed by rural inhabitants themselves, are actually "run by NGOs. Millions of dollars. Proposals. And funding. I don't know what. And media. If I donate, I want to see the tree, I want to see the forest, the billboards, et cetera. And it's like going against what I think it should be."

Language occupies an important dimension of her current research, as she seeks to name places and refer to nature in the terms that reflect connections of local populations with nature. Discussing nature reserves, she says they often have names understandable to an international scientific community, but "before it wasn't like this. It was an area, a place. It had a name ... sometimes it had the name of (the plant) [but] sometimes it had like 'the Valley of the Mosquitoes'-it was a place."

The issue is that when you think about the connection of people with nature, the language also is a major issue, because if you say "biodiversity" it's a common thing: "biodiversity." People say it. But in Arabic, it sounds very scientific. And then "nature" you can say "nature" or "environment"-it's different. I felt that maybe what I want is to ask people, "what do you call that?" and see what they call it. And then I use what they call it.... [In] one of the surveys I did ... I asked them "where is nature?" So, a lot of them said "in the olive groves." So, for them, cultivated terraces are nature. So, this is rural (nature). We cannot say that nature is only the protected areas.

Talhouk chafes at how academic work is evaluated. In her own experience, the evidence-based projects she works on do not fit easily into conventional measures of academic production. She notes:

It's really intriguing that it takes much more effort to relay information to the general public but there is no way that it is evaluated. It looks like outreach, service. It's not looked at as anything that is important, but I am doing it all the time ... I feel this is serving the society. 


\section{Discussion and Conclusion}

Our aim in this study has been to pose questions about how we conceptualize writing in the disciplines when viewed from the perspective of world-systems analysis. We have sought to illustrate how some scholars' work is specifically shaped by their own sense of semiperipheral location. Those who recognize semiperipheral characteristics in their location may gain particular insight into how the core operates and be well placed to recognize behaviours and assumptions in the core that otherwise remain tacit. This sensitivity may cause them to challenge such behaviours and assumptions; it may also make them astute teachers and academic mentors for new scholars joining their context.

For the four other academics who participated in our original project, but are not presented in our analysis, the tensions we attribute to semiperipheral location are not evident in their interview responses, and we must consider why this is so. As noted, our data were not collected with the intention of investigating our participants' relationships with their working context, assuming it to be in the semiperiphery. While general topics were suggested to participants, they were not asked to respond on set themes, and the scope of the interview was unconstrained. Each interview therefore followed its own path. We cannot know whether an interviewee who did not talk about issues that relate to the semiperiphery would never do so; indeed, they may have strong opinions that simply went unexpressed during the interview. Based on our existing data, these four other participants do not view themselves as in a different situation from others in their discipline, wherever they may be based. They recognize that there may be some drawbacks to working at an institution in the semiperiphery, but these do not have a fundamental impact on what they can achieve. For example, the scientist recognizes practical limitations, such as needing government permission to import special laboratory supplies, but is able to work around such problems without compromising her research with international collaborators.

The four scholars whose interviews we did not represent in this chapter are connected globally and work globally, each seeing their own field of study as a shared, international endeavour. Their academic training was within this network, and they continue to engage with the core regardless of physical location. Two participants in particular, a linguist and an anthropologist, also recognize that working at AUB ideally situates them to undertake the particular research and teaching they are most interested in. Their working context provides access to data that they use to contribute to a global disciplinary conversation. This is different from the relationship described by Salma Talhouk, where the work of an academic researcher in "a developing country" 
cannot resemble a colleague's work in a core context, because scholars outside core contexts must "do what needs to be done." She asserts a fundamentally different position for herself in relation to a broader discipline. Although it was materially possible for her to conduct the same research that a scientist in "the Midwest" conducts, to do so made no sense to her. Similarly, Sari Hanafi's research challenges both basic disciplinary assumptions in his field and conditions of social research in this region. To explain this range of evidence, we return to the principles of world-systems analysis, which state that categories of core, periphery, and semiperiphery are not territorial locations and are not static; instead, they are formed by relations across locations. Based on this principle, it is likely that scholars in the same institution or nation will experience a particular location differently: for some it will have characteristics attributed to the semiperiphery and for others it will operate like an institution in the core.

Bringing the interview data into focus through the lens of the semiperiphery discloses how a scholar's sense of their relationship with their discipline may play a significant role in intellectual understanding, scholarly production, and participation. It allows the semiperiphery to be characterized in the way articulated by Bennett (2014), as "a place of tension ... effervescent with possibilities, allowing dominant attitudes to be challenged and new paradigms to arise" (p. 7). Much core-periphery literature has focused on material conditions and issues around the language of knowledge production for publication, although researchers may also indicate that they recognize some of the broader disparities that a world-systems analysis perspective has foregrounded in our own study (e.g., and somewhat controversially, Hyland, 20I6). However, the experiences related by our participants show how a semiperiphery context can also represent challenges to core disciplinary assumptions, disciplinary boundaries, or institutional practices, especially related to scholar evaluation.

As teachers of academic writing who work with students and faculty members in many fields, we are led to conceptualize disciplinarity and the roles writing plays in creating and sharing different areas of knowledge. Like the work of Gere et al. (2015) and Tusting and Barton (2016), our analysis in this paper urges us to be conscious of the variations within and across disciplines, and to understand disciplinary practices as shaped by a complex of factors including material and socio-political ones. The ruptures and tensions we have highlighted in our interview data are played out at the level of disciplinarity. These scholars' accounts strongly reaffirm the centrality of writing in performing disciplinary knowledge. At the same time, however, writing is also represented as a site for contesting what are often deeply rooted config- 
urations, for working out tensions within a discipline, and for challenging the values and approaches of that discipline.

Wallerstein (2016) insists on framing world-systems analysis as an analytical approach, not a theory with the sense of closure a theory implies. $\mathrm{He}$ prefers his approach to serve as a means to continue probing the complex relationships between the social, the cultural, and the political domains that have been difficult to link together, assigned as they are to their own disciplinary spaces. The interconnections and interdependencies between core, periphery and semiperiphery posited by world-systems analysis suggest that disciplinary work in any location can be queried through this approach. This framing suggests questions that may be useful for all teachers of academic writing and scholars to consider. We have drawn these from our initial engagement, through this paper, with some concepts from world-systems analysis in the field of academic and disciplinary writing:

- How do I see myself situated in core-periphery terms? Would this look different from someone else's perspective? How do I present myself to those I teach and mentor?

- Have I considered my academic role in terms of my relationships with core and periphery and with a globalized academia?

- Where do I look for exemplars, good practice and professional expectations?

- To what extent am I aware of tension between institutional or disciplinary expectations and my own goals or the goals of my students?

- What affordances does my working context give me that I might contest core expectations and assumptions?

Naturally, each of us will respond differently to these questions depending on our professional context and perspective, and no claim is made of there being "correct answers." The views of the four scholars presented in this paper indicate some of the many dimensions along which we might place ourselves with our own responses. Sirène Harb questions what is currently valued in her discipline while concurrently working to help her students join that same disciplinary conversation. Saouma BouJaoude consciously aligns his research to appeal to institutional and disciplinary orientations towards the core. Salma Talhouk challenges the conventional focus of academic effort and production, as she seeks to situate her work and create local impact. Sari Hanafi does not shy away from controversy as he pushes disciplinary boundaries, skillfully adapting his writing to reach non-academic audiences. While the complexity and contradiction of these positions might be seen as symptomatic of a particularly complicated, and sometimes testing, semiperipheral context, we 
should not be surprised if our own reflections on the questions set provoke similarly challenging and critical perspectives, whether we locate our work in a core, peripheral, or semiperipheral situation.

\section{Acknowledgments}

We are indebted to our eight research participants and colleagues for their expert insight, generosity, and patience. We are grateful for funding for this project through a Scholarship of Teaching and Learning grant from the Center for Teaching and Learning at the American University of Beirut (2016-20I7).

\section{References}

American University of Beirut. (2019). American University of Beirut: Facts and figures 2019. https://www.aub.edu.lb/AboutUs/Documents/FactsFigures-2019.pdf

Anderson, B. S. (2011). The American University of Beirut: Arab nationalism and liberal education. University of Texas $\operatorname{Pr}$ is envisaged is an ess.

Babones, S. J., \& Chase-Dunn, C. (Eds.). (2012). The Routledge handbook of worldsystems analysis. Routledge.

Bazerman, C., \& Paradis, J. (Eds.). (1991). Textual dynamics of the professions: Historical and contemporary studies of writing in professional communities. University of Wisconsin Press.

Bennett, K. (Ed.). (2014). The semiperiphery of academic writing. Palgrave Macmillan. Canagarajah, A. S. (2002). A geopolitics of academic writing. Pittsburgh University Press.

Esseili, F. (2017). A sociolinguistic profile of English in Lebanon. World Englishes, 36(4), 684-704. https://doi.org/10.1111/weng.12262

Flowerdew, J., \& Costley, T. (Eds.). (2017). Discipline-specific writing: Theory into practice. Routledge.

Gere, A. R., Swofford, S. C., Silver, N., \& Pugh, M. (2015). Interrogating disciplines/disciplinarity in WAC/WID: An institutional study. College Composition and Communication, 67(2), 243-266. https://www.jstor.org/ stable/24633857

Hanafi, S. (2014). Al-Akhta’ al-sha’i a fi kitabat makalat al-bahth al-ijtima i [Common mistakes in sociological writing]. Idafat: The Arab Journal of Sociology, 26-27, 6-11.

Hyland, K. (2016). Academic publishing and the myth of linguistic injustice. Journal of Second Language Writing, 31, 58-69. https://doi.org/10.1016/j.jslw.2016.01.005

Lillis, T., \& Curry, M. J. (2010). Academic writing in a global context: The politics and practices of publishing in English. Routledge.

Orr, M., \& Annous, S. (2018). There is no alternative! Student perceptions of learning in a second language in Lebanon. Journal of Language and Education, 4(1), 79-91. https://doi.org/10.17323/2411-7390-2018-4-1-79-91 
Prior, P. A. (1998). Writing/disciplinarity: A sociobistorical account of literate activity in the academy. Routledge.

Russell, D. R. (2002). Writing in the academic disciplines: A curricular bistory $\left(2^{\text {nd }} e d.\right)$. Southern Illinois University Press.

Salloum, S., \& BouJaoude, S. (2020). Language in teaching and learning science in diverse Lebanese multilingual classrooms: Interactions and perspectives. International Journal of Science Education, 42(14), 2331-2363. https://doi.org/10.10 80/09500693.2019.1648909

Shaaban, K. (2017). The ongoing rivalry between English and French in Lebanon. In A. Gebril (Ed.), Applied linguistics in the Middle East and North Africa (pp. 161-182). John Benjamins.

Talhouk, S. N. (2017). Alif ba' al-tabi a [The ABCs of nature]. Arab Scientific Publishers.

Talhouk, S. N., Yazbek, M. M., Sleem, K., Sarkissian, A. J., Al-Zein, M. S., \& Abou Eid, S. (2014). Ashjar Lobnan [Trees of Lebanon]. Nature Conservation Center, American University of Beirut.

Thaiss, C., \& Zawacki, T. M. (2006). Engaged writers and dynamic disciplines: Research on the academic writing life. Boynton/Cook Publishers.

Tusting, K., \& Barton, D. (2016). Writing disciplines: Producing disciplinary knowledge in the context of contemporary higher education. Ibérica: Revista de la Asociación Europea de Lenguas para Fines Especificos, 32, 15-34. http://www.aelfe. org/documents/32_01_IBERICA.pdf

Wallerstein, I. (2004). World-systems analysis: An introduction. Duke University Press.

Wallerstein, I. (2011) Thinking about the humanities. In D. Palumbo-Lui, B. Robbins, \& N. Tanoukhi (Eds.), Immanuel Wallerstein and the problem of the world: System, scale, culture (pp. 223-226). Duke University Press. https://doi. org/10.1215/9780822393344-011

Wallerstein, I. (2012). Conclusion: World-systems analysis as a knowledge movement. In S. J. Babones \& C. Chase-Dunn (Eds.), The Routledge handbook of world-systems analysis (pp. 515-521). Routledge. https://doi. org/10.4324/9780203863428.ch15_7

Wallerstein, I. (2016). The itinerary of world-systems analysis; or, how to resist becoming a theory. In I. Wallerstein, C. A. Aguirre Rojas, \& C. Lemert (Eds.), Uncertain worlds: World-systems analysis in changing times (pp. 195-217). Routledge. 